\title{
Introducing a Bariatric Surgery Program at a Large Urban Safety Net Medical Center Serving a Primarily Hispanic Patient Population
}

\author{
Tayler J. James $^{1}$ (D) Stephen F. Sener ${ }^{1} \cdot$ James D. Nguyen $^{1} \cdot$ Marc Rothschild $^{1} \cdot$ Lauren Hawley $^{1} \cdot$ Tanu A. Patel $^{1}$. \\ Rachel Sargent ${ }^{1} \cdot$ Adrian Dobrowolsky $^{1}$
}

Received: 9 March 2021 / Revised: 11 June 2021 / Accepted: 16 June 2021 / Published online: 2 July 2021

(C) The Author(s), under exclusive licence to Springer Science+Business Media, LLC, part of Springer Nature 2021

\begin{abstract}
Background Few bariatric surgery programs exist at safety net hospitals which often serve patients of diverse racial and socioeconomic backgrounds. A bariatric surgery program was developed at a large urban safety net medical center serving a primarily Hispanic population. The purpose of this study was to evaluate safety, feasibility, and first-year outcomes to pave the way for other safety net bariatric programs.

Methods The bariatric surgery program was started at a safety net hospital located in a neighborhood with over twice the national poverty rate. A retrospective review was performed for patient demographics, comorbidities, preoperative diet and exercise habits, perioperative outcomes, and 1-year outcomes including percent total weight lost (\%TWL) and comorbidity reduction.

Results A total of 153 patients underwent laparoscopic sleeve gastrectomy from May 2017 through December 2019. The average preoperative BMI was $47.9 \mathrm{~kg} / \mathrm{m}^{2}$, and $54 \%$ of patients had diabetes. The 1 -year follow-up rate was $94 \%$. There were no mortalities and low complication rates. The average 1 -year $\%$ TWL was $22.8 \%$. Hypertension and diabetes medications decreased in $52 \%$ and $55 \%$ of patients, respectively. The proportion of diabetic patients with postoperative $\mathrm{HbA} 1 \mathrm{c} \leq 6.0 \%$ was $49 \%$.

Conclusion This is one of the first reports on the outcomes of a bariatric surgery program at a safety net hospital. This analysis demonstrates feasibility and safety, with no mortalities, low complication rates, and acceptable \%TWL and comorbidity improvement. More work is needed to investigate the impacts of race, culture, and socioeconomic factors on bariatric outcomes in this population.
\end{abstract}

Keywords Bariatric surgery $\cdot$ Sleeve gastrectomy $\cdot$ Safety net hospital $\cdot$ Disparities $\cdot$ Hispanic

\section{Introduction}

\section{Key Points}

- Implementing a bariatric program at a safety net hospital is safe and feasible and addresses disparities in bariatric surgery utilization seen in the USA.

- In our study of 1-year sleeve gastrectomy outcomes in a primarily Hispanic safety net population, weight loss and diabetes remission rates were comparable to those reported in the literature.

- More work is needed to investigate the impacts of race, culture, and socioeconomic factors on bariatric outcomes in our safety net population.

Tayler J. James

Tayler.james@med.usc.edu

1 Department of Surgery, LAC+USC Medical Center, University of Southern California, 1510 San Pablo Street, HCC I, Suite 514, Los Angeles, CA 90033, USA
Bariatric surgery is the most effective treatment for severe obesity. It results in significant weight loss, reduction of obesity-related comorbidities and mortality, and improvement in quality of life compared to non-surgical treatment [1-6]. Bariatric surgery has become increasingly popular over recent years. In 2018, over 252,000 bariatric procedures were performed in the USA, which is a $10.8 \%$ increase from 2017 and a $60 \%$ increase from 2011 [7]. Despite its growing popularity, only approximately $1 \%$ of patients who qualify for bariatric surgery ever receive it [7].

Most bariatric surgery programs exist at community or university-based hospitals [8, 9]. Few are at safety net hospitals, which by legal mandate or mission provide care for all patients regardless of insurance status or ability to pay [10]. Safety net hospitals often serve patients of diverse ethnic and 
socioeconomic backgrounds. Hispanic and black populations have a higher prevalence of severe obesity than white populations but are less likely to undergo bariatric surgery [11-13]. With the implementation of the Affordable Care Act in 2014, patients of ethnic minority and low-income backgrounds now undergo bariatric surgery more frequently than before, but still at lower proportions than their white and more affluent counterparts [14, 15]. In 2017, we developed a bariatric surgery program at our large urban safety net medical center serving a primarily Hispanic patient population. The purpose of this study was to evaluate program safety, feasibility, and firstyear outcomes to pave the way for other safety net bariatric programs and to describe outcomes in this population with unknown bariatric success.

\section{Methods}

Our safety net medical center is one of the largest in the country, with over 150,000 emergency department visits each year. The surrounding neighborhood has a poverty rate of $28.6 \%$, which is more than double the poverty rate in the USA [16]. In this neighborhood, $63 \%$ of people are Hispanic, and $71.5 \%$ of people speak a language other than English at home [16]. The bariatric program was modeled after the program at our university hospital affiliate. Bariatric-specific personnel were hired including bariatric surgeons, a bariatric nurse practitioner, a dietician, and a psychiatrist. A standardized preoperative pathway was developed including a mandatory group education seminar, psychiatric evaluation, and 6-month supervised diet and nutrition program. The seminar content and educational materials were taken from our university hospital's program and adapted by a third-party service to meet the language and reading level of the majority of our population. The seminar was administered in both English and Spanish, and all materials were printed in both languages. The 6-month preoperative program involved monthly meetings with the dietician to discuss healthy eating and lifestyle strategies such as limiting fat and sugar, decreasing portion size, and increasing exercise. A uniform postoperative care protocol was created which included a post-operative diet advancement plan, affordable protein and vitamin supplements, and dietician follow-up visits at 2 weeks, 2 months, 6 months, and annually. Given the lower income status of our population, if our patients had difficulty obtaining the recommended supplements, we offered alternative supplement options. It was decided to only perform laparoscopic sleeve gastrectomy at the initiation of the program due to its ease of operative standardization and the lower rates of postoperative complications and malnutrition compared to laparoscopic Roux-en-Y gastric bypass [17, 18]. Only first-time bariatric operations were performed.

A retrospective review was performed of a prospectively maintained database of patients who underwent bariatric surgery since the program start in 2017. Preoperative variables were extracted from the medical records including patient age, body mass index (BMI), gender, race, comorbidities, referral source, and insurance status. Information on obesity history and preoperative diet and exercise habits was obtained from dietician visit documentation. Patients on at least one medication for hypertension or diabetes were considered to have hypertension or diabetes, respectively. Perioperative outcomes included operative time, hospital length of stay, 30day complications, reoperations, and readmissions. One-year follow-up was obtained through in-person clinic visits before the coronavirus disease 2019 (COVID-19) pandemic and telephone visits during the COVID-19 pandemic. Only weights measured in clinic were used to determine weight loss. Weight loss outcomes included postoperative and programmatic average percent total weight lost (\% TWL) at 1 year. Postoperative \%TWL, defined as the percent total weight lost from surgery to 1 year, was calculated using the formula: (weight at surgery - weight at one year / weight at surgery) $\times 100$. Programmatic $\%$ TWL, defined as the percent total weight lost from the first bariatric clinic visit to 1 year, was calculated using the formula: (weight at first bariatric visit weight at one year / weight at first bariatric visit $) \times 100$. Comorbidity improvement was quantified by the decrease in number or cessation of medications after surgery. Pre- and post-operative glycated hemoglobin (HbAlc) levels were collected for all patients with diabetes.

Data analyses were conducted using SPSS (SPSS Statistics 26.0; IBM Corp, Armonk, NY). Comparisons were performed using paired T-tests. Frequencies are reported as n (\%). Parametric and non-parametric data are reported as mean + standard deviation and median (interquartile range), respectively.

\section{Results}

A total of 153 consecutive patients underwent laparoscopic sleeve gastrectomy from May 2017 through December 2019. Preoperative characteristics are described in Table 1. The mean preoperative BMI was $47.9+5.7 \mathrm{~kg} / \mathrm{m}^{2}$. There were $99(65 \%)$ patients who were Hispanic, followed by 25 $(16 \%)$ who were black and $21(14 \%)$ who were white. Hypertension was present in 108 patients (71\%), and diabetes was present in 83 patients (54\%). There were 133 patients $(87 \%)$ who were referred from their primary care provider, while the others were referred from specialty clinics such as general surgery and gynecology most commonly from within the hospital. The majority of patients were insured by MediCal, California's Medicaid program. Self-directed diet and exercise were attempted by 131 patients $(86 \%)$ for weight loss prior to evaluation for bariatric surgery, while 32 patients (21\%) participated in a formal weight loss program such as 
Table 1 Patient characteristics and preoperative diet history $(\mathrm{n}=153)$

\begin{tabular}{|c|c|}
\hline Variable & $\mathrm{N}(\%)$ \\
\hline Age $(y r s$, mean \pm SD $)$ & $47.5 \pm 9.5$ \\
\hline $\mathrm{BMI}\left(\mathrm{kg} / \mathrm{m}^{2}\right.$, mean $\left.\pm \mathrm{SD}\right)$ & $47.9 \pm 5.7$ \\
\hline Gender, female & $124(81)$ \\
\hline \multicolumn{2}{|l|}{ Race } \\
\hline Hispanic & $99(65)$ \\
\hline Black & $25(16)$ \\
\hline White & $21(14)$ \\
\hline Other & $8(5)$ \\
\hline \multicolumn{2}{|l|}{ Comorbidities } \\
\hline Hypertension & $108(71)$ \\
\hline Diabetes & $83(54)$ \\
\hline Insulin-dependent diabetes & $30(20)$ \\
\hline Obstructive sleep apnea & $23(15)$ \\
\hline Gastroesophageal reflux disease & $43(28)$ \\
\hline \multicolumn{2}{|l|}{ Referral source } \\
\hline Primary care clinic & $133(87)$ \\
\hline Specialty care clinic & $20(13)$ \\
\hline \multicolumn{2}{|l|}{ Insurance } \\
\hline Medi-Cal & $131(86)$ \\
\hline Medicare & $11(7)$ \\
\hline Uninsured & $9(6)$ \\
\hline Other publicly funded program & $2(1)$ \\
\hline Private & $0(0)$ \\
\hline \multicolumn{2}{|l|}{ Onset of obesity } \\
\hline Adulthood & $50(32)$ \\
\hline Adolescence & $27(18)$ \\
\hline Childhood & $76(50)$ \\
\hline \multicolumn{2}{|l|}{ Prior diet attempts ${ }^{\mathrm{a}}$} \\
\hline Self-directed diet/exercise & $131(86)$ \\
\hline Formal weight loss program & $32(21)$ \\
\hline Medication & $21(14)$ \\
\hline None & $4(2)$ \\
\hline \multicolumn{2}{|l|}{ Habits contributing to obesity ${ }^{a}$} \\
\hline Junk food & $133(87)$ \\
\hline Frequent snacking & $89(58)$ \\
\hline Overeating & $81(53)$ \\
\hline Emotional eating & $74(48)$ \\
\hline Sedentary lifestyle & $5(3)$ \\
\hline \multicolumn{2}{|l|}{ Reasons for desired weight loss ${ }^{\mathrm{a}}$} \\
\hline Improve health/longevity & $108(71)$ \\
\hline Improve pain/mobility & $46(30)$ \\
\hline Improve self-esteem & $14(9)$ \\
\hline Qualify for other surgery & $12(8)$ \\
\hline
\end{tabular}

${ }^{\text {a }}$ Percent totals may add up to greater than 100 because patients could report more than one answer

Weight Watchers or Jenny Craig. Junk food, frequent snacking, overeating, and emotional eating were commonly reported habits that likely contributed to obesity. The most common reported reason for desired weight loss was to improve health or longevity, reported by 108 patients $(71 \%)$. Other reasons included to improve pain or mobility $(\mathrm{n}=46.30 \%)$, to improve self-esteem $(\mathrm{n}=14.9 \%)$, and to qualify for another surgery such as hernia repair or knee replacement $(\mathrm{n}=12.8 \%)$.

Perioperative outcomes are outlined in Table 2. Average operative time was 125 (104-153) min. Operative complications included two conversions to open, one for bleeding and one for incorporation of the esophageal temperature probe into the gastric staple line. Thirty-day postoperative complications included two unplanned admissions to the intensive care unit for hypotension $(1.3 \%)$ and two venous thromboembolic events (VTE, 1.3\%). Reoperation was required in six patients: four for staple line bleeding (2.6\%), one for portal vein thrombosis and ischemic bowel (0.7\%), and one for stent placement for per oral intolerance $(0.7 \%)$. The most common reasons for readmission were abdominal pain and nausea/vomiting managed conservatively.

One-year follow-up was available for 144 patients (94\%). Measured 1-year weights were available in 98 patients (64\%). Average 1-year postoperative \%TWL from surgery to 1 year was $22.8 \pm 8.8 \%$. Average programmatic $\% \mathrm{TWL}$, which included weight lost during the 6-month preoperative interval, was $27.1 \pm 8.8 \%(\mathrm{p}<0.01)$ (Table 3$)$. One-year comorbidity outcomes are described in Table 4. Of patients with preoperative hypertension, $56(52 \%)$ required fewer antihypertensive medications at 1 year, and $35(32 \%)$ were off all antihypertensives. The change in number of hypertension medications is presented in Figure 1. Of patients with preoperative diabetes, $46(55 \%)$ decreased their diabetes medication, and $31(37 \%)$ completely stopped. Fifteen of the 30 patients (50\%) with insulin-dependent diabetes were completely off insulin 1 year after surgery. The change in number of diabetes medications is presented in Figure 2. Fifty-eight (70\%) patients had a HbA1c of 6.5 or less 1 year after surgery, and $41(49 \%)$ had a HbA1c of 6.0 or less. The average HbA1c in patients with diabetes dropped from $8.3 \% \pm 1.0$ preoperatively to $6.7 \% \pm$ 1.2 after surgery $(\mathrm{p}<0.01)$ (Figure 3$)$.

Table 2 Perioperative outcomes $(n=153)$

\begin{tabular}{ll}
\hline Outcome & $\mathrm{N}(\%)$ \\
\hline Operative time (minutes, median [IQR]) & $125[104-153]$ \\
Hospital length of stay (hours, median [IQR]) & $52[34-59]$ \\
Operative complications & $2(1.3)$ \\
30-day postoperative complications & $4(2.6)$ \\
Reoperations & $6(4)$ \\
Readmissions & $11(7)$ \\
Mortality & $0(0)$ \\
\hline
\end{tabular}


Table 3 Average 1-year weight loss ( $\mathrm{n}=98)$

\begin{tabular}{|c|c|}
\hline Weight loss variable & $\% \pm \mathrm{SD}$ \\
\hline Postoperative $\% \mathrm{TWL}^{\mathrm{a}}$ & $22.8+8.8$ \\
\hline Programmatic $\% \mathrm{TWL}^{\mathrm{b}}$ & $27.1 \pm 8.8$ \\
\hline
\end{tabular}

$P$ value $<0.01$

${ }^{a}$ Percent total weight lost from date of surgery to 1 year after surgery

${ }^{\mathrm{b}}$ Percent total weight lost from beginning of bariatric program to 1 year after surgery

\section{Discussion}

To our knowledge, this is one of the first reports on the development and outcomes of a bariatric surgery program at a large urban safety net medical center. This analysis demonstrates feasibility and safety, with no mortalities and low overall complication rates similar to the literature $[15,19,20]$. The VTE rate of $1.3 \%$ is at the higher end of the $0.3-2.2 \%$ range reported in the literature $[15,21,22]$. All patients were placed on perioperative chemical VTE prophylaxis. The relatively high VTE rate could be due in part to the high risk of our population, as our average starting BMI and diabetes prevalence was higher than those described in many other bariatric studies, including specifically Hispanic populations [19, 20, 23-28]. Our bleed rate of $2.6 \%$ is also slightly higher than other studies of sleeve gastrectomy which report rates up to $2.5 \%$ [20, 29]. This could potentially be due to the learning curve at the start of the program and/or the teaching nature of our hospital which involves a high level of trainee autonomy. At the end of 2019, we began routinely using bioabsorbable staple line reinforcement for all cases, and since then we have had no staple line bleeds.

The 1-year follow-up rate of $94 \%$ was higher than expected in this population that likely faces barriers to obtaining consistent healthcare. The low 1-year weight measurement rate of $64 \%$ can be attributed to restrictions in in-person visits due to the COVID-19 pandemic. The average operative time of $125 \mathrm{~min}$ for laparoscopic sleeve gastrectomy may be a product of the teaching hospital environment. The \% TWL at 1 year

Table 4 One-year comorbidity outcomes

\begin{tabular}{ll}
\hline Variable & $\mathrm{N}(\%)$ \\
\hline Fewer hypertension medications & $56 / 108(52 \%)$ \\
No hypertension medication & $35 / 108(32 \%)$ \\
Fewer diabetes medications & $46 / 83(55 \%)$ \\
No diabetes medication & $31 / 83(37 \%)$ \\
Insulin-dependent diabetics off insulin & $15 / 30(50 \%)$ \\
Postoperative HbA1c $\leq 6.5$ & $58 / 83(70 \%)$ \\
Postoperative HbA1c $\leq 6.0$ & $41 / 83(49 \%)$ \\
\hline
\end{tabular}

was $22.8 \%$, which is near the $23-34 \%$ reported in other studies [30-32]. Over half of patients decreased their diabetes medication 1 year after surgery, and $37 \%$ completely stopped. A few recent trials report diabetes remission after bariatric surgery of up to $60 \%$ at 1 year; however, it is difficult to compare diabetes remission across studies given variability in the definition of "remission" [23, 33, 34]. In the STAMPEDE trial by Schauer et al. comparing bariatric surgery with medical therapy on diabetes outcomes, the primary outcome was $\mathrm{HbA} 1 \mathrm{c} \leq 6.0 \%$, which was met by $37 \%$ in the sleeve gastrectomy group [1]. In our study, $49 \%$ of patients met this criteria.

Our population was comprised of $67 \%$ Hispanic patients. The Hispanic population is the fastest-growing ethnic minority group in the USA, now comprising $18.4 \%$ of the total population [35]. Studies have shown obesity is more prevalent among ethnic minority populations, yet these patients are less likely to undergo bariatric surgery than their white counterparts [36-40]. In an analysis of the National Inpatient Sample, Kroner Florit et al. found that Hispanic patients undergo bariatric surgery at an odds ratio of 0.88 compared to nonHispanic patients [41]. This underutilization in the Hispanic population is likely multifactorial. Compared to the nonHispanic population, overweight and obese Hispanic Americans are less likely to try to lose weight and/or seek professional help in losing weight [39]. Hispanic patients are also less likely to be referred to bariatric surgery than nonHispanic patients [27]. While the reasons for this are not completely understood, patient factors (such as language/ cultural barriers preventing patients from seeking bariatric referrals) and system factors (such as lack of referral offered by primary care provider) likely contribute [27]. By developing a bariatric program within our patients' existing medical community, we addressed some of these barriers. It is easy for primary care providers to refer to our program since we are located within the same county-sponsored health system. Many of our clinic staff speak fluent Spanish and have experience in our safety net setting, which decreases the language and cultural barriers that may exist for our patients at other programs.

Patients of minority backgrounds and low socioeconomic status undergo bariatric surgery at higher rates than before; however, these patients often demonstrate worse outcomes than their white counterparts. This has been consistently demonstrated in black patients, yet the effect on Hispanic patients has been less clear [19, 42-44]. While some studies show less weight loss in Hispanic patients when compared to white patients after bariatric surgery, others show similar weight and comorbidity improvement between the two groups [42-44]. When specifically evaluating blood lipid profiles, Istfan et al. found that although all races had significant improvements in blood lipids 2 years after Roux-en-Y gastric bypass, Hispanics had an increase in total cholesterol and low-density 
Figure 1 Change in hypertension medications before and after surgery
60

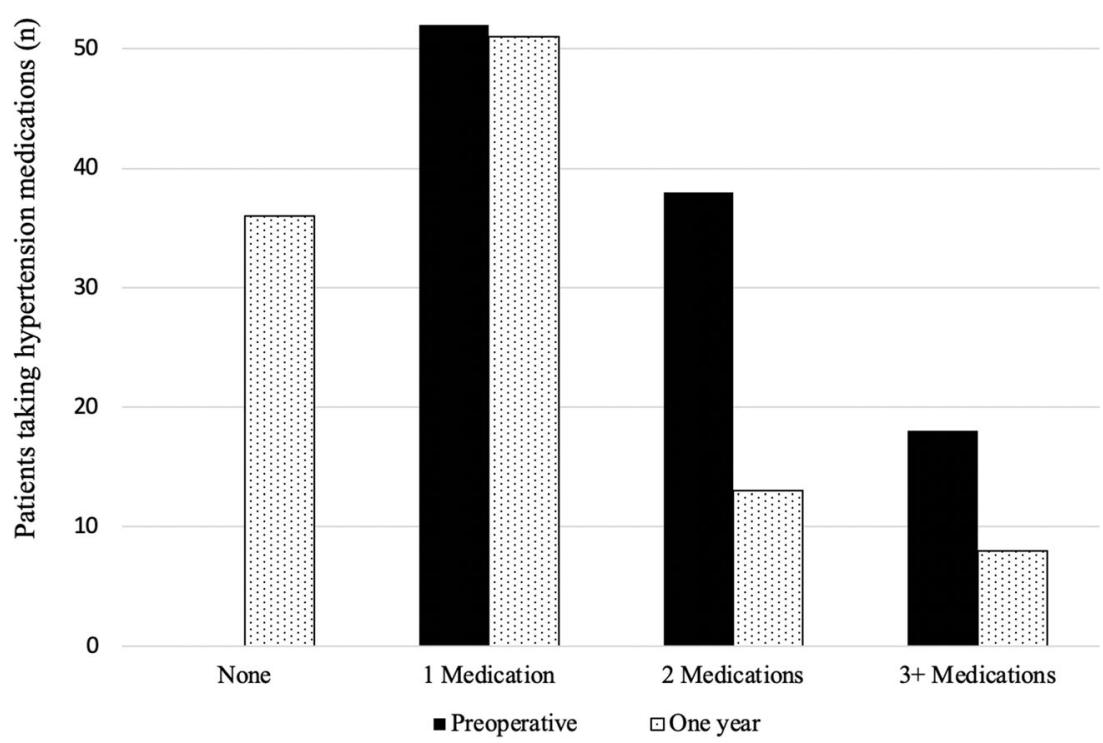

lipoprotein when compared to white and black patients [24]. Income has also been identified as a significant predictor of weight loss after bariatric surgery, with lower-income patients exhibiting lower weight loss [13]. Although we did not collect income data on our patients, we anticipate many of our patients come from low-income neighborhoods given the location of our hospital. In our study, 1-year weight loss and diabetes remission were similar to other reports in the literature. This is notable given our population's average starting BMI and diabetes prevalence was higher than those described in many bariatric studies [19, 20, 23-28]. Also notable, the programmatic \%TWL, which includes the weight lost during the 6-month preoperative period, was $4.3 \%$ higher than the $\%$ TWL after surgery $(\mathrm{p}<0.01)$. This suggests the 6-month program of supervised diet, exercise, and nutrition counseling contributes to overall weight loss in our program, which may be especially important in this population with limited resources. More work is needed to identify the specific impacts of race and socioeconomic status on bariatric outcomes in our patient population.

This study has limitations. First, sleeve gastrectomy was the only bariatric procedure performed. The true differences in long-term weight loss and comorbidity reduction after sleeve gastrectomy compared to gastric bypass are currently
Figure 2 Change in diabetes medications before and after surgery

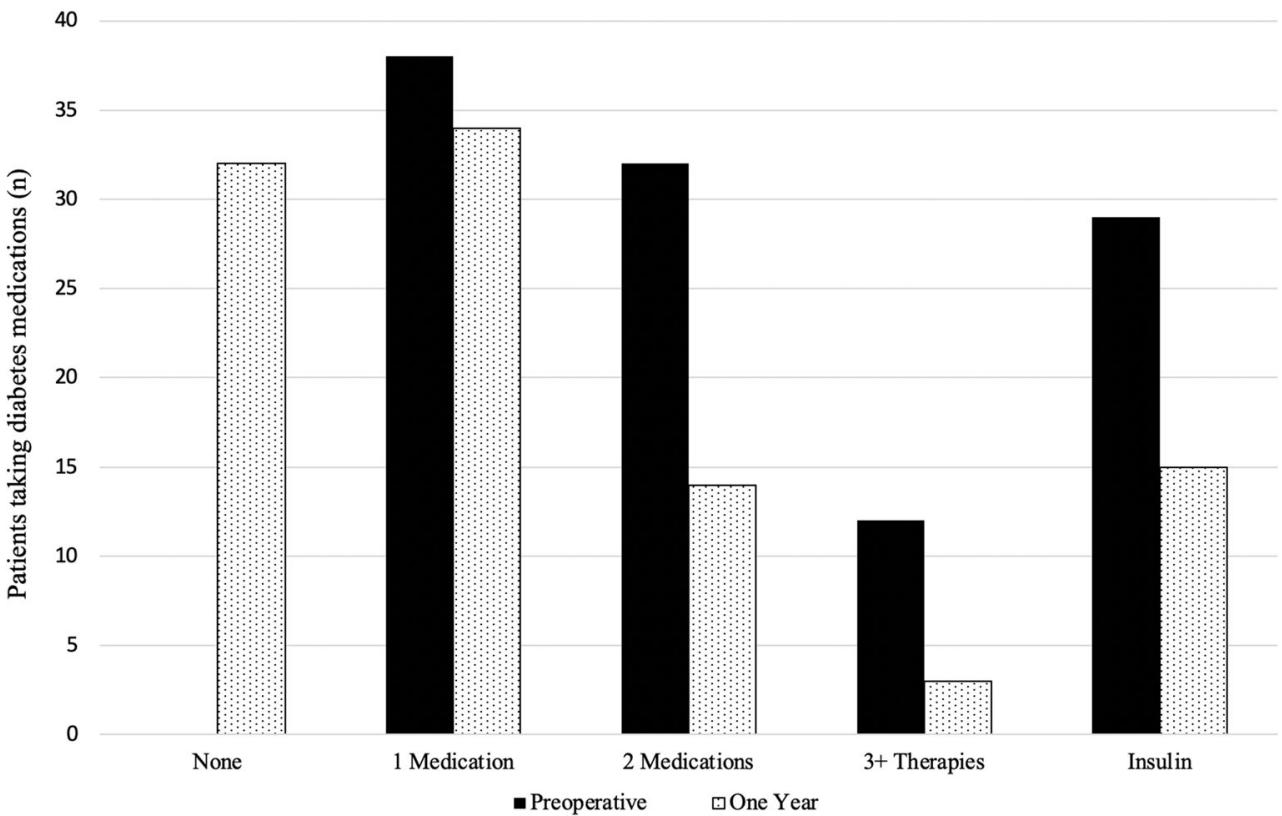


Figure 3 Change in mean glycated hemoglobin $(\mathrm{HbAlc})$ $(\mathrm{p}<0.01)$

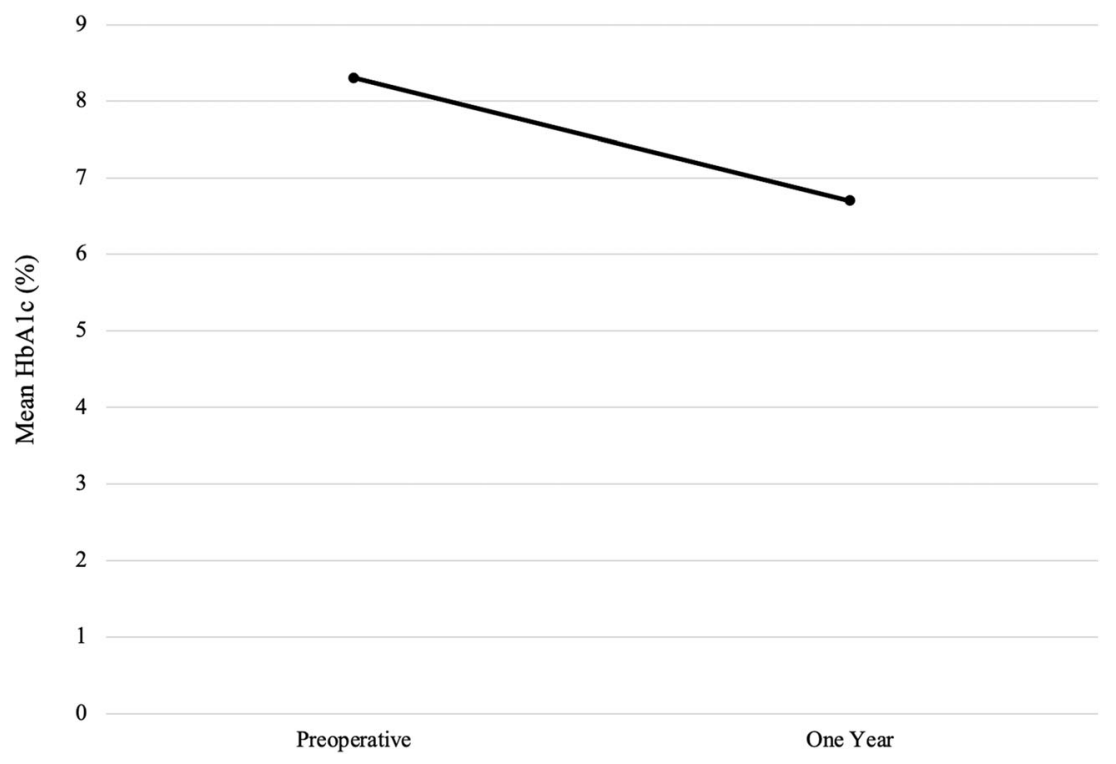

unknown due to the recent gain in popularity of the sleeve; however, it has been shown that gastric bypass provides better comorbidity remission in certain patients [20, 23]. Now that safety and effectiveness have been demonstrated, gastric bypass will be implemented on a case-by-case basis in our program. Second, this analysis includes 1 -year weight loss in only $64 \%$ of the patient population due to in-person clinic cancellations during the COVID-19 pandemic. However, we were able to contact $94 \%$ of patients via telephone to assess comorbidity improvements at 1 year. Lastly, this experience represents only that of a single safety net hospital. The population in this study consists of a unique mix of racial and socioeconomic backgrounds and may not be generalizable to other safety net populations.

\section{Conclusion}

Safety net hospitals provide care to all patients, regardless of insurance status or ability to pay. Patients who are treated at safety net hospitals are often from low socioeconomic backgrounds and unable to pay for healthcare at other facilities. Therefore, the treatments available to these patients are limited to what is offered by the safety net center in their community. With the implementation of this program at our safety net medical center, bariatric surgery is now available for the large population in our community for whom this life-altering treatment was previously not an option. This treatment option is particularly important for patients of minority backgrounds and low socioeconomic status as these populations are shown to have high rates of obesity and obesity-related comorbidities [11, 45, 46]. More work is needed to investigate the impacts of race and socioeconomic factors on bariatric outcomes in our safety net population.

\section{Declarations}

Ethics Approval and Consent to Participate All procedures performed in studies involving human participants were in accordance with the ethical standards of the institutional and/or national research committee and with the 1964 Helsinki declaration and its later amendments or comparable ethical standards. For this type of study formal consent is not required.

Conflict of Interest The authors declare no competing interests.

\section{References}

1. Schauer PR, Kashyap SR, Wolski K, et al. Bariatric surgery versus intensive medical therapy in obese patients with diabetes. N Engl $\mathrm{J}$ Med. 2012;366(17):1567-76.

2. Zhang N, Maffei A, Cerabona T, et al. Reduction in obesity-related comorbidities: is gastric bypass better than sleeve gastrectomy? Surg Endosc. 2013;27(4):1273-80.

3. Schauer DP, Feigelson HS, Koebnick C, et al. Bariatric surgery and the risk of cancer in a large multisite cohort. Ann Surg. 2019;269(1):95-101.

4. Sjöström L, Peltonen M, Jacobson P, et al. Bariatric surgery and long-term cardiovascular events. JAMA. 2012;307(1):56-65.

5. Gripeteg L, Lindroos AK, Peltonen M, et al. Effects of bariatric surgery on mortality in Swedish obese subjects. N Engl J Med. 2007;357(8):741-52.

6. Versteegden DPA. Van himbeeck MJJ, Nienhuijs SW. Improvement in quality of life after bariatric surgery: sleeve versus bypass. Surg Obes Relat Dis. 2018;14(2):170-4.

7. English WJ, DeMaria EJ, Hutter MM, et al. American Society for Metabolic and Bariatric Surgery 2018 estimate of metabolic and bariatric procedures performed in the United States. Surg Obes Relat Dis. 2020;16(4):457-63. 
8. MBSAQIP accredited bariatric surgery centers. Available from: https://www.facs.org/search/bariatric-surgery-centers?allresults=

9. Madan AK, Tichansky DS, Ternovits CA, et al. Establishing a laparoscopic bariatric program in a safety net hospital. Surg Endosc. 2007;21(5):801-4.

10. M EL, S A. America's health care safety net. National Academies Press; 2000. Available from: https://pubmed.ncbi.nlm.nih.gov/ 25077222/

11. Hales CM, Carroll MD, Fryar CD, Ogden CL. Prevalence of obesity and severe obesity among adults: United States, 2017-2018. NCHS Data Brief, no 360. Hyattsville, MD: National Center for Health Statistics; 2020.

12. Martin M, Beekley A, Kjorstad R, et al. Socioeconomic disparities in eligibility and access to bariatric surgery: a national populationbased analysis. Surg Obes Relat Dis. 2010;6(1):8-15.

13. Hecht LM, Pester B, Braciszewski JM, et al. Socioeconomic and racial disparities in bariatric surgery. Obes Surg. 2020;30(6):2445-9.

14. Gould KM, Zeymo A, Chan KS, et al. Bariatric surgery among vulnerable populations: the effect of the Affordable Care Act's Medicaid expansion. Surg (United States). 2019;166(5):820-8.

15. Campos GM, Khoraki J, Browning MG, et al. Changes in utilization of bariatric surgery in the United States from 1993 to 2016. Ann Surg. 2020;271(2):201-9.

16. Los Angeles County (Central)-LA City (East Central/Central City \& Boyle Heights) PUMA, CA - Profile data - Census Reporter. Available from: https://censusreporter.org/profiles/ 79500US0603744-los-angeles-county-central-la-city-eastcentralcentral-city-boyle-heights-puma-ca/

17. Courcoulas A, Coley RY, Clark JM, et al. Interventions and operations 5 years after bariatric surgery in a cohort from the US National Patient-Centered Clinical Research Network Bariatric Study. JAMA Surg. 2020;155(3):194-204.

18. Antoniewicz A, Kalinowski P, Kotulecka KJ, et al. Nutritional deficiencies in patients after Roux-en-Y gastric bypass and sleeve gastrectomy during 12-month follow-up. Obes Surg. 2019;29(10): 3277-84.

19. Wood MH, Carlin AM, Ghaferi AA, et al. Association of race with bariatric surgery outcomes. JAMA Surg. 2019;154(5):1-8.

20. Salminen P, Helmio M, Ovaska J, et al. Effect of laparoscopic sleeve gastrectomy vs laparoscopic roux-en-y gastric bypass on weight loss at 5 years among patients with morbid obesity the SLEEVEPASS randomized clinical trial. JAMA. 2018;319(3): 241-54.

21. Froehling DA, Daniels PR, Mauck KF, et al. Incidence of venous thromboembolism after bariatric surgery: a population-based cohort study. Obes Surg. 2013;23(11):1874-9.

22. Bartlett MA, Mauck KF, Daniels PR. Vascular health and risk management Dovepress Prevention of venous thromboembolism in patients undergoing bariatric surgery. Vasc Health Risk Manag. 2015:11-461.

23. Peterli R, Wolnerhanssen BK, Peters T, et al. Effect of laparoscopic sleeve gastrectomy vs laparoscopic roux-en-y gastric bypass on weight loss in patients with morbid obesity: the SM-BOSS randomized clinical trial. JAMA. 2018;319(3):255-65.

24. Istfan N, Anderson WA, Apovian C, et al. Racial differences in weight loss, hemoglobin $\mathrm{A} 1 \mathrm{C}$, and blood lipid profiles after Roux-en-Y gastric bypass surgery. Surg Obes Relat Dis. 2016;12(7):1329-36.

25. Stanford FC, Jones DB, Schneider BE, et al. Patient race and the likelihood of undergoing bariatric surgery among patients seeking surgery. Surg Endosc. 2015;29(9):2794-9.

26. Sundaresan N, Roberts A, Thompson KJ, et al. Examining the Hispanic paradox in bariatric surgery. Surg Obes Relat Dis. 2020;16(10):1392-400.
27. Johnson-Mann C, Martin AN, Williams MD, et al. Investigating racial disparities in bariatric surgery referrals. Surg Obes Relat Dis. 2019;15(4):615-20.

28. Wee CC, Huskey KW, Bolcic-Jankovic D, et al. Sex, race, and consideration of bariatric surgery among primary care patients with moderate to severe obesity. J Gen Intern Med. 2014;29(1):68-75.

29. Bransen J, Gilissen LPL, van Rutte PWJ, et al. Costs of leaks and bleeding after sleeve gastrectomies. Obes Surg. 2015;25(10):1767-71.

30. Sczepaniak JP, Owens ML, Shukla H, et al. Comparability of weight loss reporting after gastric bypass and sleeve gastrectomy using BOLD data 2008-2011. Obes Surg. 2015;25(5):788-95.

31. Arterburn DE, Johnson E, Coleman KJ, et al. Weight outcomes of sleeve gastrectomy and gastric bypass compared to nonsurgical treatment. Ann Surg. 2020:1-8.

32. Wang X, Chang X, sheng, et al. Effectiveness of laparoscopic sleeve gastrectomy for weight loss and obesity-associated co-morbidities: a 3-year outcome from Mainland Chinese patients. Surg Obes Relat Dis. 2016;12(7):1305-11.

33. Courcoulas AP, Gallagher JW, Neiberg RH, et al. Bariatric surgery vs lifestyle intervention for diabetes treatment: 5 -year outcomes from a randomized trial. J Clin Endocrinol Metab. 2020;105(3)

34. Mingrone G, Panunzi S, De Gaetano A, et al. Bariatric-metabolic surgery versus conventional medical treatment in obese patients with type 2 diabetes: 5 year follow-up of an open-label, single-centre, randomised controlled trial. Lancet. 2015;386(9997):964-73.

35. ACS demographic and housing estimates. Available from: https:// data.census.gov/cedsci/table?q=hispanic\&tid=ACSDP1Y2019. DP05\&hidePreview=false

36. Forrest KYZ, Leeds MJ, Ufelle AC. Epidemiology of obesity in the Hispanic adult population in the United States. Fam Community Heal. 2017;40(4):291-7.

37. Hales CM, Carroll MD, Fryar CD, et al. Prevalence of obesity among adults and youth: United States, 2015-2016. NCHS data brief, no 288. Hyattsville, MD: National Center for Health Statistics. NCHS Data Brief. 2017;(288):1-8.

38. Byrd AS, Toth AT, Stanford FC. Racial disparities in obesity treatment. Curr Obes Rep. 2018;7(2):130-8.

39. Marquez B, Murillo R. Racial/ethnic differences in weight-loss strategies among US adults: National Health and Nutrition Examination Survey 2007-2012. J Acad Nutr Diet. 117(6):923-8.

40. Wallace AE, Young-Xu Y, Hartley D, et al. Racial, socioeconomic, and rural-urban disparities in obesity-related bariatric surgery. Obes Surg. 2010;20(10):1354-60.

41. Kröner Florit PT, Corral Hurtado JE, Wijarnpreecha K, et al. Bariatric surgery, clinical outcomes, and healthcare burden in Hispanics in the USA. Obes Surg. 2019;29(11):3646-52.

42. Cheung LK, Lal LS, Chow DSL, et al. Racial disparity in shortterm outcomes after gastric bypass surgery. Obes Surg. 2013;23(12):2096-103

43. Valencia A, Garcia LC, Morton J. The impact of ethnicity on metabolic outcomes after bariatric surgery. J Surg Res. 2019;236:345-51.

44. Elli EF, Gonzalez-Heredia R, Patel N, et al. Bariatric surgery outcomes in ethnic minorities. Surg (United States). 2016;160(3):805-12.

45. CDC. National Diabetes Statistics Report 2020. Estimates of diabetes and its burden in the United States. 2020.

46. Ostchega Y, Fryar CD, Nwankwo T, Nguyen DT. Hypertension prevalence among adults aged 18 and over: United States, 2017 2018 key findings data from the National Health and Nutrition Examination Survey. 2017. Available from: https://www.cdc.gov/ nchs/products/index.htm.

Publisher's Note Springer Nature remains neutral with regard to jurisdictional claims in published maps and institutional affiliations. 